\title{
Deletion of Cu/Zn Superoxide Dismutase Gene sodC Reduces Aspergillus niger Virulence on Chinese White Pear
}

\author{
Chen Chen ${ }^{1}$, Meng-Ke Zhang ${ }^{1}$, Kang-Di Hu ${ }^{1}$, Ke-Ke Sun, Yan-Hong Li, Lan-Ying Hu, \\ and Xiao-Yan Chen \\ School of Food Science and Engineering, Hefei University of Technology, Hefei, Anhui 230009, \\ People's Republic of China \\ Ying Yang \\ College of Environment and Energy Engineering, Anhui Jianzhu University, Hefei, Anhui 230022, \\ People's Republic of China \\ Feng Yang and Jun Tang \\ Xuzhou Institute of Agricultural Sciences of the Xuhuai District of Jiangsu Province, Xuzhou, \\ Jiangsu 221131, People's Republic of China \\ He-Ping Liu \\ Anhui Siping Food Development Co. Ltd., Tongling, Anhui 244100, People's Republic of China
}

Hua Zhang
School of Food Science and Engineering, Hefei University of Technology, Hefei, Anhui 230009,
People's Republic of China

ADDITIONAL INDEX wORDs. homologous recombination, oxidative stress, fungal sporulation, fruit-pathogen interaction, pathogenicity

\begin{abstract}
Aspergillus niger is a common pathogenic fungus causing postharvest rot of fruit and vegetable, whereas the knowledge on virulence factors is very limited. Superoxide dismutase [SOD (EC 1.15.1.10)] is an important metal enzyme in fungal defense against oxidative damage. Thus, we try to study whether $\mathrm{Cu} / \mathrm{Zn}-\mathrm{SOD}$ is a virulence factor in $\mathrm{A}$. niger. $\mathrm{Cu} / \mathrm{Zn}$-SOD encoding gene sodC was deleted in $A$. niger [MA70.15 (wild type)] by homologous recombination. The deletion of sodC led to decreased SOD activity in $A$. niger, suggesting that sodC did contribute to full enzyme activity. $\Delta$ sod $C$ strain showed normal mycelia growth and sporulation compared with wild type. However, sodC deletion markedly increased the cell's sensitivity to intracellular superoxide anion generator menadione. Besides, spore germination under menadione and $\mathrm{H}_{2} \mathrm{O}_{2}$ stresses were significantly retarded in $\triangle \mathrm{sod} C$ mutant compared with wild type. Further results showed that sodC deletion induced higher superoxide anion production and higher content of $\mathrm{H}_{2} \mathrm{O}_{2}$ and malondialdehyde (MDA) compared with wild type, supporting the role of SOD in metabolism of reactive oxygen species (ROS). Furthermore, $\triangle$ sodC mutant had a reduced virulence on chinese white pear (Pyrus bretschneideri) as lesion development by $\Delta$ sodC was significantly less than wild type. The determination of superoxide anion, $\mathrm{H}_{2} \mathrm{O}_{2}$, and MDA in $A$. niger-infected pear showed that chinese white pear infected with $\triangle$ sod $C$ accumulated less superoxide anion, $\mathrm{H}_{2} \mathrm{O}_{2}$, and MDA compared with that of wild type $A$. niger, implying that $\Delta$ sodC induced an attenuated response in chinese white pear during fruit-pathogen interaction. Our results indicate that sodC gene contributes to the full virulence of $A$. niger during infection on fruit. Aspergillus niger is one of the most common species found in fungal communities. It is an important fermentation industrial strain and is also known to cause the most severe symptoms in fruit during long-term storage (Pel et al., 2007). Meanwhile, plants activate their signaling pathways to trigger defense responses to limit pathogen expansion. One of the earliest host responses after pathogen attack is oxidative burst, during which large quantities of ROS are generated by different host enzyme systems, such as glucose oxidase (Govrin and Levine, 2000). ROS such as singlet oxygen, superoxide anion, hydroxyl $\left(\mathrm{OH}^{-}\right)$, and $\mathrm{H}_{2}$ $\mathrm{O}_{2}$ are released to hinder the advance of pathogens (Gara et al., 2003). ROS can react with and damage cellular molecules, such as DNA, protein, and lipids, which will limit fungal propagation in the host plant (Apel and Hirt, 2004).
\end{abstract}

Many antioxidant enzymes in fungal pathogens participate in reactive oxygen degradation on plant-released ROS. Among them, SODs are metalloenzymes that form the primary cellular

Received for publication 16 May 2017. Accepted for publication 20 July 2017. Funding for this work was provided by the National Natural Science Foundation of China (31670278, 31470013, 31300133), the earmarked fund for China Agriculture Research System CARS-10-B1, Anhui Provincial Science and Technology Major Project (6030701073) and Anhui Provincial Education Department (KJ2015ZD12).

${ }^{1}$ These authors contributed equally to this work.

${ }^{2}$ Corresponding author. E-mail: hzhanglab@hfut.edu.cn. antioxidant defense system by catalyzing the superoxide disproportionation (a type of redox reaction) to produce molecular oxygen and $\mathrm{H}_{2} \mathrm{O}_{2}$, which is further catalyzed by peroxidase and catalase (Vallino et al., 2009). SOD activity is usually induced along with overproduction of superoxide anions (Benes et al., 1995; Gupta et al., 1993). Cu/Zn-SOD is a kind of SOD, which is commonly present in the cytoplasm of eukaryotic cells. It is composed of two subunits which contain one $\mathrm{Cu}^{2+}$ and one $\mathrm{Zn}^{2+}$, respectively. Some progress has been made in the research of $\mathrm{Cu} / \mathrm{Zn}-\mathrm{SOD}$ (SOD1, also known as 
CCS1) in Saccharomyces cerevisiae and Candida albicans (Gleason et al., 2014). In S. cerevisiae, a mutant with deletion of $\mathrm{Cu} / \mathrm{Zn}-\mathrm{SOD}$ is oxygen-sensitive, hypermutable, defective in sporulation (Liu et al., 1992). In the major human fungal pathogen $C$. albicans, $\mathrm{Cu} / \mathrm{Zn}$-SOD mutant shows delayed hyphal growth on Spider medium (a medium to stimulate hyphal growth and colony wrinkling in C. albicans) and higher sensitivity to menadione, a redox-cycling agent (Hwang et al., 2002). The deletion of bcsodl in the necrotrophic fungal pathogen Botrytis cinerea causes smaller lesion on pea (Pisum sativum) leaves, which proves that this gene is essential for full virulence of B. cinerea on plants (Rolke et al., 2004). However, Moore et al. (2002) found that the $\mathrm{Cu} / \mathrm{Zn}$ SOD cpsodl gene in Claviceps purpurea is not essential for pathogenicity in rye (Secale cereal), and deletion of cpsodl caused no increased sensitivity to paraquat, a generator of superoxide, suggesting that the function of $\mathrm{Cu} / \mathrm{Zn} \mathrm{SOD}$ in fungi is not always conserved or the functions of relative genes are redundant. In $A$. niger, we identified sodC as a homology of SOD1 in $S$. cerevisiae. However, how A. niger induces responses in fruit and whether $\operatorname{sod} C$ is a virulence factor for $A$. niger infection on fruit are still unclear.

Some molecular biological manipulation techniques for filamentous fungi have been applied in A. niger, such as gene knockout, transformation, and dominant selectable markers (Delmas et al., 2014). In this work, we constructed the deletion mutant $\Delta$ sodC by homologous recombination. Then, the role of sodC gene in fungal resistance to oxidative stress was examined, and the infection ability of $\Delta \operatorname{sod} C$ mutant on chinese white pear fruit was analyzed.

\section{Materials and Methods}

Strains, Plasmid, And Growth COnditions. Aspergillus niger MA 70.15 ( $\operatorname{pyy} G$, pyrG encodes orotidine-5-phosphate decarboxylase, cell lacking this enzyme cannot grow without exogenous uridine, but can resist toxicity of 5-fluoroorotic acid) was used as wild type strain in this work. Generally, A. niger was grown on potato dextrose agar medium supplemented with uridine $\left\{\right.$ PDA-Uri $\left[200 \mathrm{~g} \cdot \mathrm{L}^{-1}\right.$ potato (Solanum tuberosum), $20 \mathrm{~g} \cdot \mathrm{L}^{-1}$ agar, $20 \mathrm{~g} \cdot \mathrm{L}^{-1}$ glucose, $10 \mathrm{mmol} \cdot \mathrm{L}^{-1}$ uridine $\left.]\right\}$ at $28^{\circ} \mathrm{C}$ or liquid PDA-Uri medium.

Construction of $\Delta$ SodC mutant. The gene sodC deletion mutant was constructed according to the procedure by Delmas et al. (2014). To delete the sodC gene in $A$. niger, upstream and downstream fragments $\mathrm{AB}$ (902 bp) and CD (502 bp) were amplified by polymerase chain reaction (PCR) from $A$. niger MA70.15 genomic DNA. The upstream and downstream fragments contained a common restriction site HindIII which was used to ligate the two fragments together and restriction sites EcoRI and XhoI, respectively. EcoRI and XhoI restriction sites on the ligated fragment ABCD were used for cloning into the plasmid pC3 (Delmas et al., 2014) to create pC3-An_AsodC integrative plasmid. Primers are shown as following (bp with underline indicates restriction site): sodC-A (5'-CCGGAATTCATCCAGTGGGTGACCAAGTA-3'); sodC-B (5' CTCAAAGCTTCACCTCCAGAATGCTACTTT-3'); sodC-C (5'-GGTGAAGCTTTGAGTAGTCTGCCATTATCCC-3'); and sodC-D (5'-CCGCTCGAGGGCTCTTTCCCGATCATAT-3').

Then, the pC3-An_AsodC integrative plasmid was transformed into the $A$. niger MA70.15 ( $\Delta p y r G$ ) strain by polyethylene glycol-mediated transformation of protoplasts according to Ballance and Turner (1985). The gene pyrG encoding for the orotidine-5-phosphate decarboxylase was chosen as a counter-selection marker (Boeke et al., 1984). Transformed clones were confirmed by PCR of genomic DNA to identify the $\operatorname{sod} C$ deletion mutant (Delmas et al., 2014).

DNA EXTRACTION AND THE CONFIRMATION OF $\triangle$ SODC STRAIN. Genomic DNA of $A$. niger was extracted using Master Pure Yeast DNA Purification Kit (Epicentre, Madison, WI). Primers sodC-A and sodC-D flanking the sodC gene were used as external primers, and primers sodC-F (5'-TCGTTGGATCTCGTGGTT-3') and sodC-R (5' -TCTTGGACTCCTCGTTGC$\left.3^{\prime}\right)$ designed on the open reading frame (ORF) of sodC gene were used to determine whether the $\operatorname{sod} C$ gene was deleted or not.

RNA EXTRACTION AND QUANTITATIVE REVERSE TRANSCRIPTASEPCR (Q-PCR). Conidia at $0.1 \mathrm{~g}$ of the wild type $A$. niger MA 70.15 and $\triangle$ sod $C$ grown on PDA-Uri solid medium for $5 \mathrm{~d}$ were harvested. Then, they were ground to powder under liquid nitrogen. Total RNA and cDNA were obtained according to the instructions of RNAiso plus (TaKaRa, Tokyo, Japan) (van Leeuwen et al., 2013) and Prime Script RT Master Mix (TaKaRa), respectively. The procedure of q-PCR was as follows: denaturation at $95^{\circ} \mathrm{C}$ for $3 \mathrm{~min}$, followed by cycles of $95^{\circ} \mathrm{C}$ for $10 \mathrm{~s}, 60^{\circ} \mathrm{C}$ for $30 \mathrm{~s}$, and $72^{\circ} \mathrm{C}$ for $10 \mathrm{~s}$, cycled for 40 times. The primers used for q-PCR were shown below: sodC-S (5'-GAGTAGTCTGCCATTATCCC-3') and sodC-A (5'-CTCGAGGCTCTTTCCCGATCATAT- $\left.3^{\prime}\right)$. The expression of actin-encoding gene $A n 03 e 03160$ was used as a control (Raulo et al., 2016). The primers used for actin-encoding gene were actin-F $\left(5^{\prime}-\mathrm{ACG}\right.$ CTTGGACTGTGCCTC-3') and actin-R (5'-CAATGGTTCGGGTATGTGC-3').

Determination of SOD ACTIVITY. Mycelia of the wild type $A$. niger MA 70.15 and $\triangle$ sodC grown in PDA-Uri liquid medium for $3 \mathrm{~d}$ were harvested and washed three times with sterile distilled water. Frozen $A$. niger mycelia at $1 \mathrm{~g}$ was ground to powder under liquid nitrogen using a mortar and pestle and $50 \mathrm{~mm}$ ice-cold phosphate buffer (pH 7.8, $1 \mathrm{~mm}$ EDTA, $1 \mathrm{~mm}$ PMSF) was added to $5 \mathrm{~mL}$. The mixture was centrifuged at $12,000 g_{n}$ at $4{ }^{\circ} \mathrm{C}$ for $10 \mathrm{~min}$ to obtain the supernatant which was used for the determination of SOD activity by procedures described by Beauchamp and Fridovich (1971). One SOD unit was defined as the amount of enzyme that inhibits the rate of nitroblue tetrazolium reduction by $50 \%$. Activity was expressed as units per milligram protein. Protein content was measured according to Bradford (1976) using bovine serum albumin as standard.

Growth analysis of $\boldsymbol{A}$. NIGER. The conidia of the wild type $A$. niger MA 70.15 and $\triangle$ sodC grown on PDA-Uri solid medium for $5 \mathrm{~d}$ were harvested. After removal of mycelia, spore concentration was measured using a haemocytometer and adjusted to the final concentration of $10^{6}$ spores $/ \mathrm{mL}$ (Lazar et al., 2008). Then, 5- $\mu \mathrm{L}$ spore suspension of the wild type and $\triangle$ sodC were inoculated on PDA-Uri solid medium and medium supplemented with $0.02 \mathrm{~mm}$ menadione and were cultured at $28^{\circ} \mathrm{C}$ in darkness for $4 \mathrm{~d}$. Colony diameter of $A$. niger was determined every $24 \mathrm{~h}$.

The spore suspension $\left(10^{6}\right.$ spores $\left./ \mathrm{mL}\right)$ of wild type $A$. niger and $\Delta \operatorname{sod} C$ at $200 \mu \mathrm{L}$ were inoculated to $20-\mathrm{mL}$ PDA-Uri liquid medium, respectively, and were cultured at $28{ }^{\circ} \mathrm{C}$ for $150 \mathrm{rpm}$ in the thermostatic shaker. Dry weight of the mycelia of the $A$. niger was measured every $12 \mathrm{~h}$ according to the method in (Angelova et al., 2005).

Determination of SPORE Germination. Ten microliters of spore suspension $\left(10^{6}\right.$ spores $\left./ \mathrm{mL}\right)$ for the wild type $A$. niger and 
$\Delta$ sodC were placed on a $7-\mathrm{mm}-$ diameter plug of PDA-Uri supplemented with freshly-prepared $0.02 \mathrm{~mm}$ menadione and $2 \mathrm{~mm} \mathrm{H}_{2}$ $\mathrm{O}_{2}$ which were then placed on a glass slide. Menadione and $\mathrm{H}_{2} \mathrm{O}_{2}$ were added to PDA-Uri agar medium when the autoclaved medium was cooled down to $60{ }^{\circ} \mathrm{C}$. Each plugslide was held in a petri dish with moistened filter paper and then was incubated at $28{ }^{\circ} \mathrm{C}$. Conidia germination (germ tube longer than two times the diameter of the corresponding spore) of the wild type $A$. niger and $\Delta$ sodC which were in PDA-Uri culture medium (for 16 h), medium supplemented with $2 \mathrm{~mm} \mathrm{H}_{2} \mathrm{O}_{2}$ (for $24 \mathrm{~h}$ ), or medium supplemented with $0.02 \mathrm{~mm}$ menadione (for $30 \mathrm{~h}$ ) were assessed under a compound microscope at $400 \times$ total magnification with $40 \times$ of the objective lens and $10 \times$ of eyepiece lens (Fu et al., 2014).

DETERMINATION OF SUPEROXIDE ANION PRODUCTION AND CONTENT OF $\mathrm{H}_{2} \mathrm{O}_{2}$ AND MDA IN $A$. NIGER AND CHINESE WHITE PEAR SUBJECTED TO A. NIGER INFECTION. A volume of $200-\mu \mathrm{L}$ spore suspention $\left(10^{6}\right.$ spores $/ \mathrm{mL}$ ) of wild type and $\Delta \operatorname{sod} C$ was inoculated to $20-\mathrm{mL}$ PDA-Uri liquid medium and cultured at $28^{\circ} \mathrm{C}$ for $3 \mathrm{~d}$. Then, the medium was supplemented with $0.02 \mathrm{~mm}$ menadione and sampled at 12 and $24 \mathrm{~h}$. Freshly cultured $A$. niger mycelia at $1 \mathrm{~g}$ was ground to the powder under liquid nitrogen using a mortar and pestle. After A. niger inoculation on chinese white pear fruit for $3 \mathrm{~d}$, pear flesh $2 \mathrm{~cm}$ far from lesion was sampled for assay and uninoculated pear was used as control. Content of superoxide anion, $\mathrm{H}_{2} \mathrm{O}_{2}$, and MDA were determined according to the methods described by $\mathrm{Hu}$ et al. (2012).

INFECTION ABILITY OF $\boldsymbol{A}$. NIGER ON CHINESE WHITE PEAR. Chinese white pear fruit were supplied by the Anhui Academy of Agricultural Sciences, Hefei, Anhui, China. Unwounded, healthy fruit of uniform size, color, and weight were selected for experiments. Chinese white pear fruit were washed with tap water and surface-sterilized with $75 \%$ ethanol. Then, the surface of the fruit was wounded at 5 sites on each fruit. After air-drying, each of
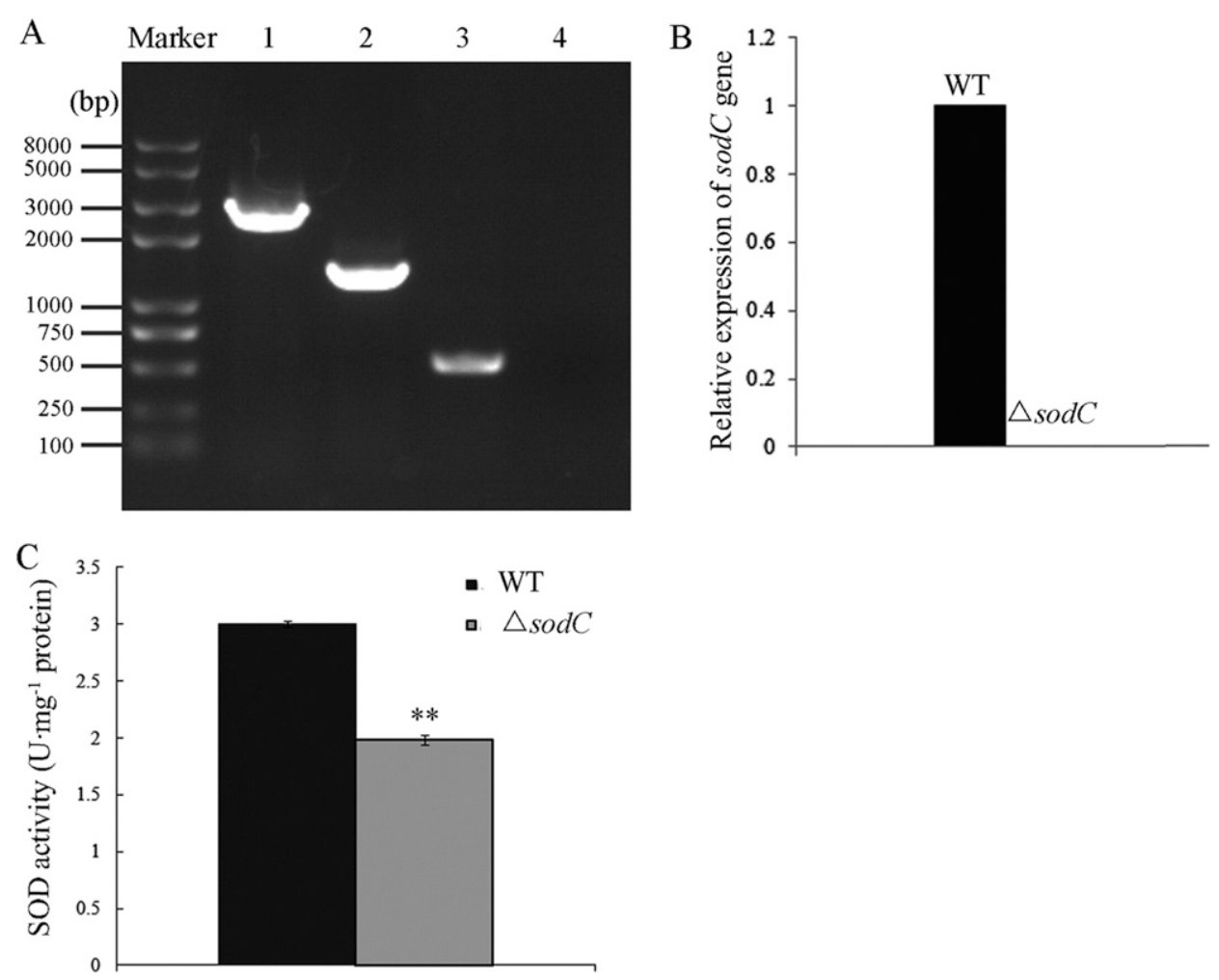

Fig. 1. The identification of the deletion mutant $\Delta \operatorname{sod} C$ and the assays of $\operatorname{sod} C$ gene expression and superoxide dismutases (SOD) activity in $\Delta \operatorname{sod} C$ mutant. (A) Confirmation of sodC deletion mutant by polymerase chain reaction (PCR) analysis of genomic DNA from wild type Aspergillus niger MA 70.15 and $\Delta$ sodC. Lane 1 and 2, genomic PCR of $A$. niger MA 70.15 and $\Delta$ sod $C$ with external primers respectively; lane 3 and 4 , genomic PCR of A. niger MA 70.15, and $\Delta \operatorname{sod} C$ with internal primers, respectively. (B) The expression of sodC gene in wild type A. niger MA 70.15 (WT, wild type) and $\Delta$ sodC. (C) The activity assay of SOD in wild type A. niger MA 70.15 (WT) and $\Delta \operatorname{sod} C$ mutant. Values are mean $\pm \mathrm{SD}(n=3)$. The symbols * and $* *$ in this figure and following ones stand for a significant difference between two data at $P<0.05$ and $P<0.01$, respectively.
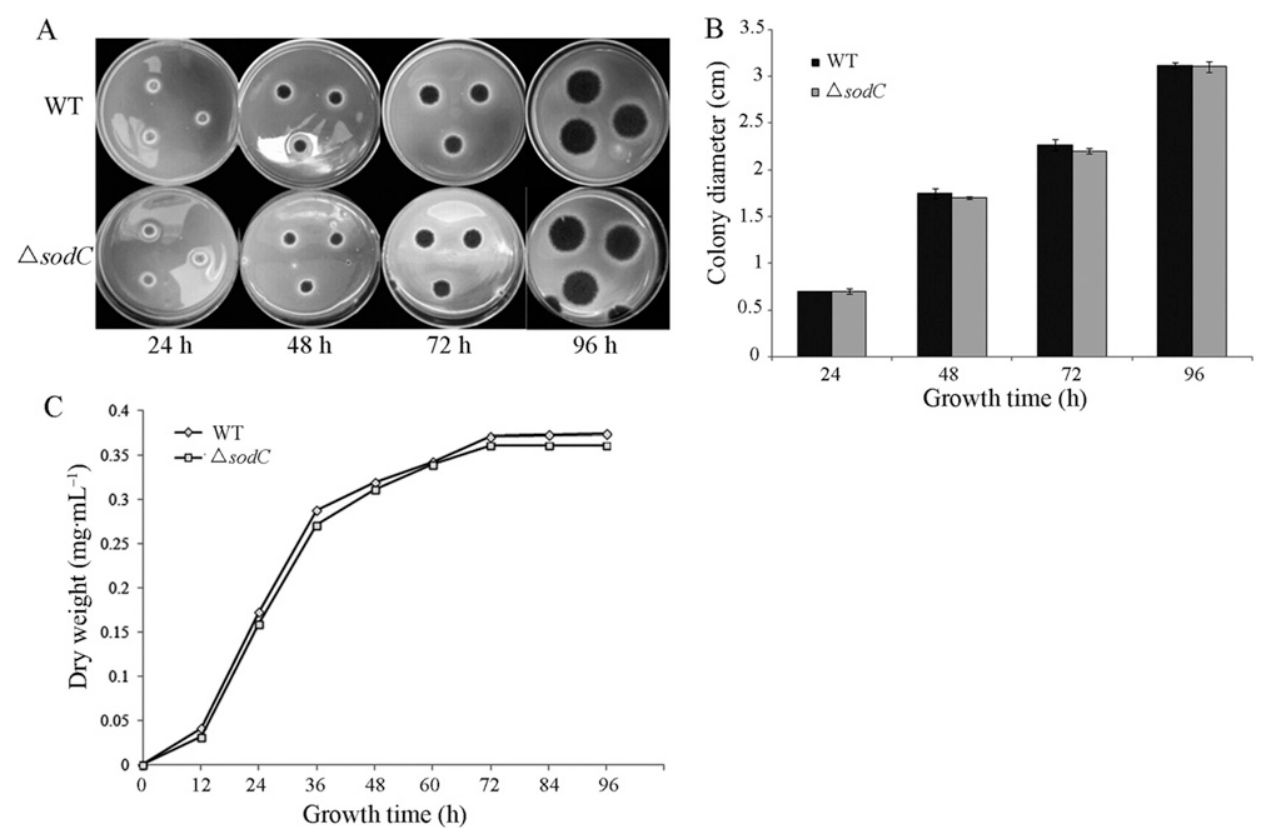

Fig. 2. Growth analysis of $\Delta$ sodC mutant on potato dextrose agar medium supplemented with uridine (PDA-Uri). (A) The mycelium growth of the wild type Aspergillus niger MA 70.15 (WT) and $\Delta$ sodC in the PDA-Uri solid medium for $96 \mathrm{~h}$. (B) The colony diameter of wild type $A$. niger MA 70.15 (WT) and the $\Delta$ sodC in A. Values are mean $\pm \mathrm{SD}(n=9)$. (C) The biomass of the wild type $A$. niger MA 70.15 (WT) and the $\Delta$ sod $C$ grown in PDA-Uri liquid culture medium for $96 \mathrm{~h}$. Values are mean $\pm \mathrm{SD}(n=3)$. 
the wounds ( $2 \mathrm{~mm}$ diameter and $4 \mathrm{~mm}$ deep) was injected with $10 \mu \mathrm{L}$ of spore suspension $\left(10^{6}\right.$ spores $\left./ \mathrm{mL}\right)$ of wild type $A$. niger and $\Delta s o d C$. Each stain was inoculated on three different fruit. Chinese white pear fruit were stored at $25{ }^{\circ} \mathrm{C}$ in sealed containers with $200 \mathrm{~mL}$ of distilled water on the bottom to maintain the relative humidity which ranged from $85 \%$ to $90 \%$ (Fu et al., 2014). The lesion diameter caused by $A$. niger was measured every $24 \mathrm{~h}$.

Statistical analysis. The data in the article are based on three replicates. Statistical significance was tested by one-way analysis of variance (ANOVA) using SPSS Statistics (version 20.0; IBM Corp., Armonk, NY), and the results were expressed as the mean $\pm \mathrm{SD}$. The least significant difference test was performed on all data after ANOVA tests to test for significant $(P<0.05$ or $P<0.01)$ differences between treatments.

\section{Results}

Construction of the $\Delta$ sodC Deletion mutant. The plasmid pC3-An_AsodC was transformed into $A$. niger MA 70.15 protoplasts. Then, the genomic DNA of transformants was extracted to identify sodC deletion mutants. As shown in Fig. $1 \mathrm{~A}$, the deletion mutant $\Delta$ sodC were confirmed by PCR with the primers sodC-A and sodC-D which flanking sodC gene and with primers sodC-F and sodC-R on the ORF of sodC gene. Thus, for the genome of wild type, the PCR product on lane 1 is about $2450 \mathrm{bp}$, and about $1400 \mathrm{bp}$ for lane 2. Because sodC gene is deleted in $\Delta s o d C$ mutant, PCR product using external primers sodC-A and sodC-D on lane 3 is about $650 \mathrm{bp}$ and there is no band on lane 4 , confirming that sodC was deleted in the mutants. Then, the gene expression of $s o d C$ in wild type and sodC deletion mutant was analyzed. As shown in Fig. 1B, sodC gene expression was not detected compared with the high expression in wild type, further confirming that sodC gene was deleted in the mutant. To study whether sodC gene actually contributes to SOD activity in the $A$. niger, total SOD activity in $\triangle \operatorname{sod} C$ was determined and compared with that in wild type. As expected, SOD activity in $\Delta$ sodC mutant $(n=9)$. was significantly lower than that of wild type $A$. niger (Fig. 1C).

Growth ANALYsis of $\Delta$ SodC Mutant. To evaluate whether the lack of $s o d C$ would affect fungal growth, we compared growth
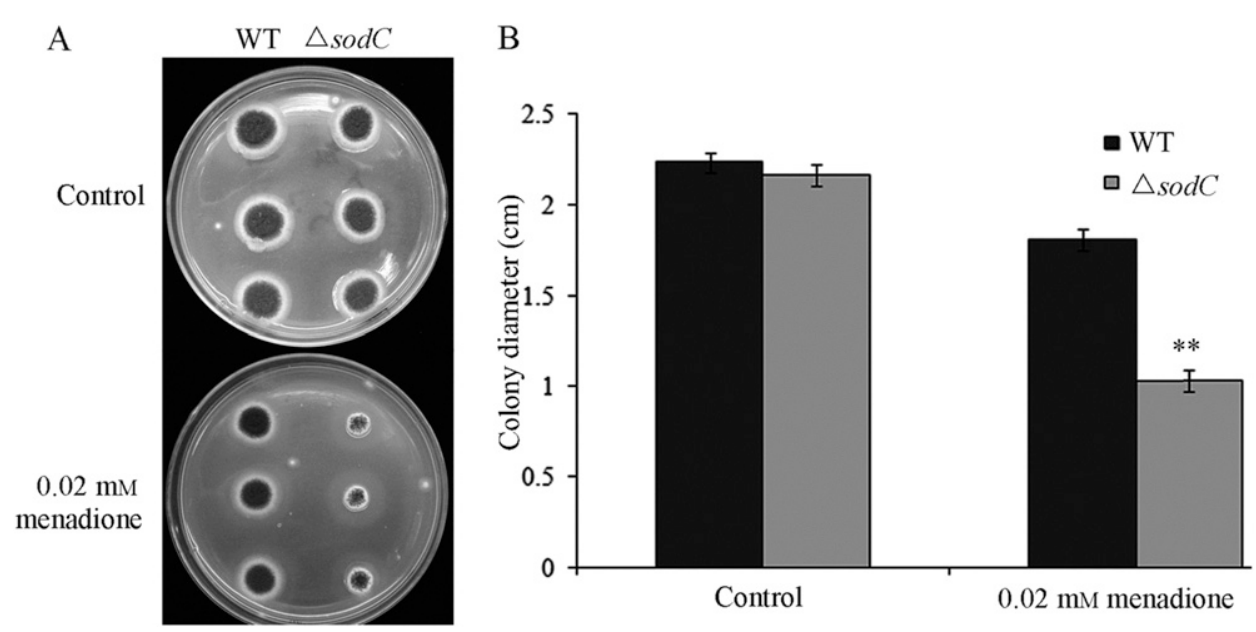

Fig. 3. The effect of menadione on the growth of the wild type Aspergillus niger MA 70.15 (WT) and $\Delta$ sodC mutant. (A) The mycelium growth of the wild type $A$. niger MA 70.15 (WT) and $\Delta$ sodC in potato dextrose agar medium supplemented with uridine (PDA-Uri) and PDA-Uri medium supplemented with $0.02 \mathrm{~mm}$ menadione for $4 \mathrm{~d}$. (B) The colony diameter of wild type A. niger MA 70.15 (WT) and $\Delta \operatorname{sod} C$ in A. Values are mean $\pm \mathrm{SD}$
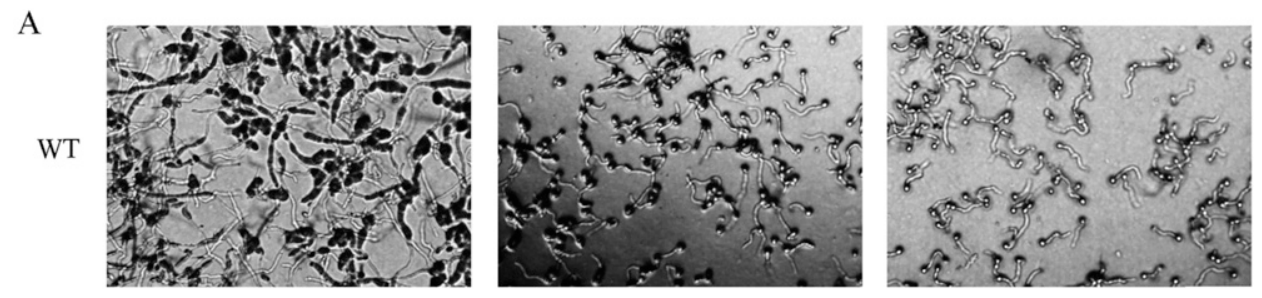

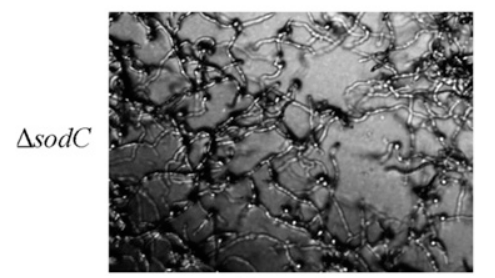

B

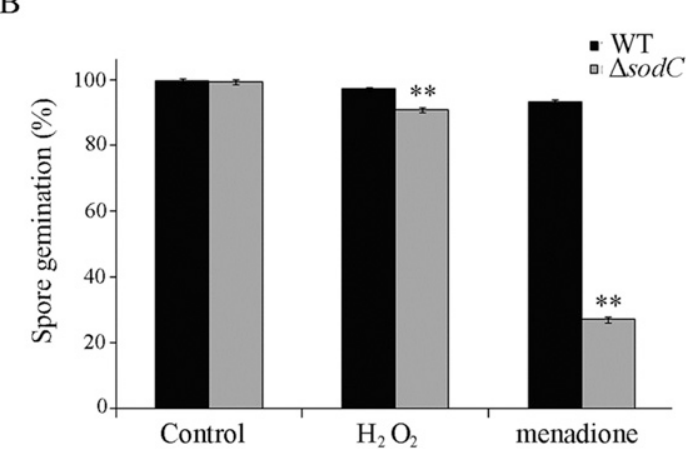

Fig. 4. The effect of menadione and $\mathrm{H}_{2} \mathrm{O}_{2}$ on the spore germination of $\Delta s o d C$. (A) The spore germination of the wild type Aspergillus niger MA 70.15 (WT) and $\Delta$ sodC mutant in potato dextrose agar medium supplemented with uridine (PDA-Uri) solid medium (16 h), PDA-Uri solid medium supplemented with $2 \mathrm{~mm} \mathrm{H}_{2} \mathrm{O}_{2}(24 \mathrm{~h})$, and supplemented with $0.02 \mathrm{~mm}$ menadione $(30 \mathrm{~h})$; bar $=100 \mu \mathrm{m}$. (B) Spore germination percentage of the wild type A. niger MA $70.15(\mathrm{WT})$ and $\Delta$ sodC in $\mathbf{A}$. Values are mean $\pm \mathrm{SD}(n=3)$. 
of $\Delta$ sodC and $A$. niger MA 70.15 on PDA-Uri medium. As shown in Fig. 2A, within $96 \mathrm{~h}$, there was no difference in the mycelial growth found between the wild type and $\triangle \operatorname{sod} C$ on PDA-Uri solid medium. Colony diameter in the wild type and the $\Delta s o d C$ also show that there is no difference in growth (Fig. 2B). Figure 2C shows that $\triangle$ sodC mutant grew normally in PDA-Uri liquid medium for $96 \mathrm{~h}$ in comparison with wild type.

SODC IN $A$. NIGER CONFERS RESISTANCE TO REACTIVE OXYGEN SPECIES. Menadione, a superoxide generating agent, was supplemented to PDA-Uri medium to evaluate whether the deletion of sodC affects the adaption of cells to oxidative stress. As shown in Fig. 3A, the mycelium growth of $\triangle \operatorname{sod} C$ was significantly retarded compared with wild type under $0.02 \mathrm{~mm}$ menadione. Figure $3 \mathrm{~B}$ shows that the colony diameter of $\Delta$ sodC was significantly smaller than that of wild type $A$. niger. However, $\Delta$ sodC mutant showed no higher sensitivity to $2 \mathrm{mM} \mathrm{H}_{2} \mathrm{O}_{2}$ stress compared with wild type (data not shown).

To further analyze the reduced growth of $\Delta s o d C$ under menadione stress, spore germination of wild type $A$. niger and $\Delta s o d C$ was analyzed under $0.02 \mathrm{~mm}$ menadione and $2 \mathrm{~mm}$ $\mathrm{H}_{2} \mathrm{O}_{2}$ stress. As shown in Fig. $4 \mathrm{~A}$ and $\mathrm{B}$, after $16 \mathrm{~h}$ of incubation in control conditions, the spores of the wild type and $\Delta \operatorname{sod} C$ all germinated. Under $0.02 \mathrm{~mm}$ menadione and $2 \mathrm{mM} \mathrm{H}_{2}$ $\mathrm{O}_{2}$ stress for 30 and $24 \mathrm{~h}$, respectively, the hyphae were obviously shorter than that in normal conditions, suggesting that $0.02 \mathrm{~mm}$ menadione and $2 \mathrm{~mm} \mathrm{H}_{2} \mathrm{O}_{2}$ effectively influenced hyphal growth of $A$. niger. After $30 \mathrm{~h}$ of $0.02 \mathrm{~mm}$ menadione stress, spore germination percentage of wild type reached $93 \%$, whereas that of $\Delta \operatorname{sod} C$ was about $27 \%$. Besides, spore germination percentage of $\Delta \operatorname{sodC}$ with $2 \mathrm{~mm} \mathrm{H}_{2} \mathrm{O}_{2}$ stress for $24 \mathrm{~h}$ was $91 \%$, which was significantly lower than $99 \%$ of the wild type $A$. niger.

Deletion of SODC ATtenuates ROS MEtabolism in $\boldsymbol{A}$. NIGER. To verify the enzymatic activity of sodC, superoxide anion production and contents of $\mathrm{H}_{2} \mathrm{O}_{2}$ and MDA were determined in menadionetreated A. niger. As shown in Fig. 5A, superoxide anion production in wild type $A$. niger increased with treatment time of menadione. Meanwhile, menadione induced significantly higher production of superoxide anion in $\Delta s o d C$ cells during the entire treatment. The significant higher level of superoxide anion was also observed in untreated $\Delta$ sod $C$ cells, suggesting that $\Delta$ sod $C$ cells may have
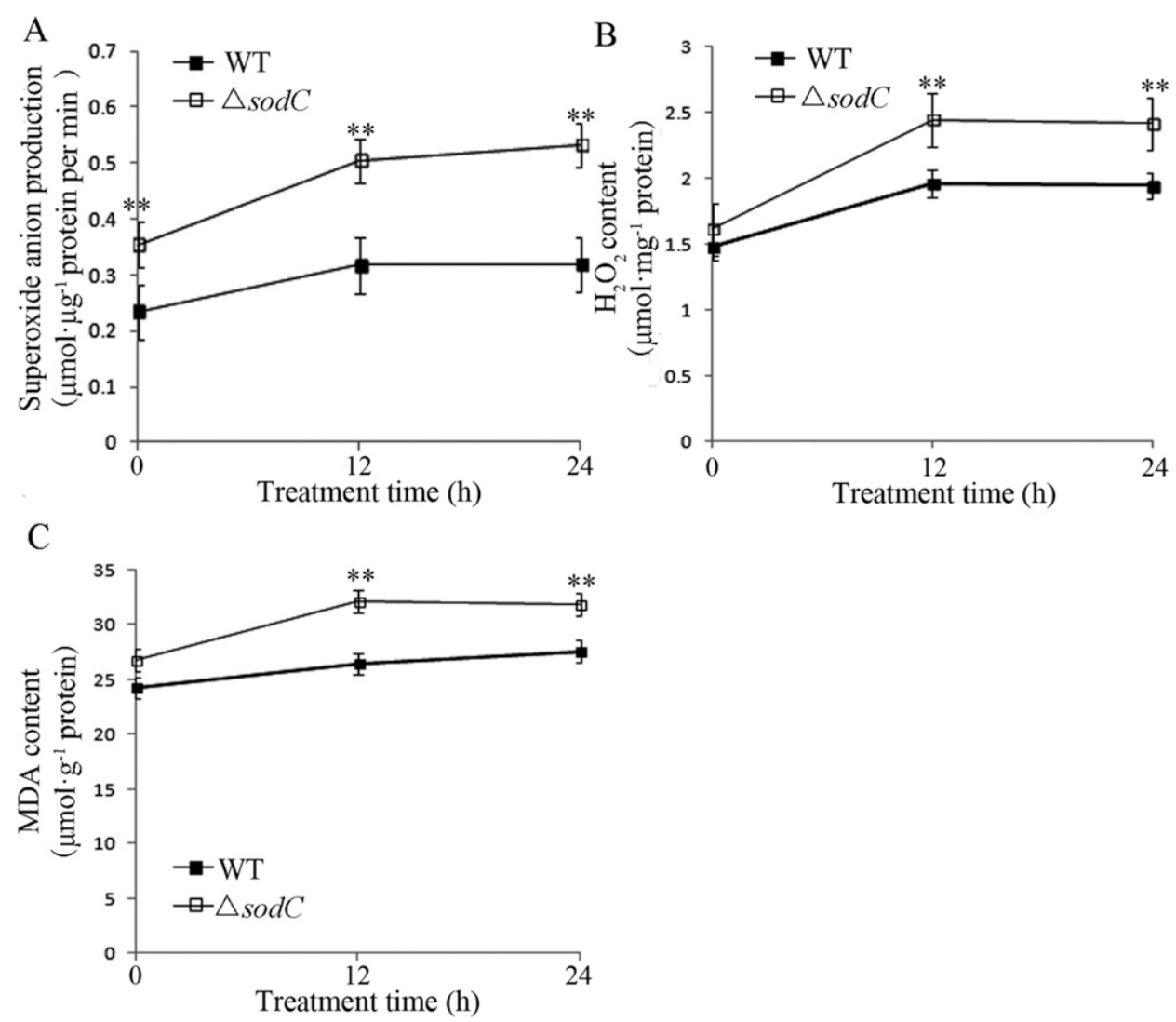

Fig. 5. The effect of menadione on the superoxide anion production (A) and content $\mathrm{H}_{2} \mathrm{O}_{2}(\mathbf{B})$ and malondialdehyde (MDA) (C) in Aspergillus niger MA 70.15 (WT) and $\Delta$ sodC were subjected to $0.02 \mathrm{~mm}$ menadione stress and sampled at 12 and $24 \mathrm{~h}$ in potato dextrose agar medium supplemented with uridine (PDAUri) liquid medium. Values are mean $\pm \operatorname{SD}(n=3)$.
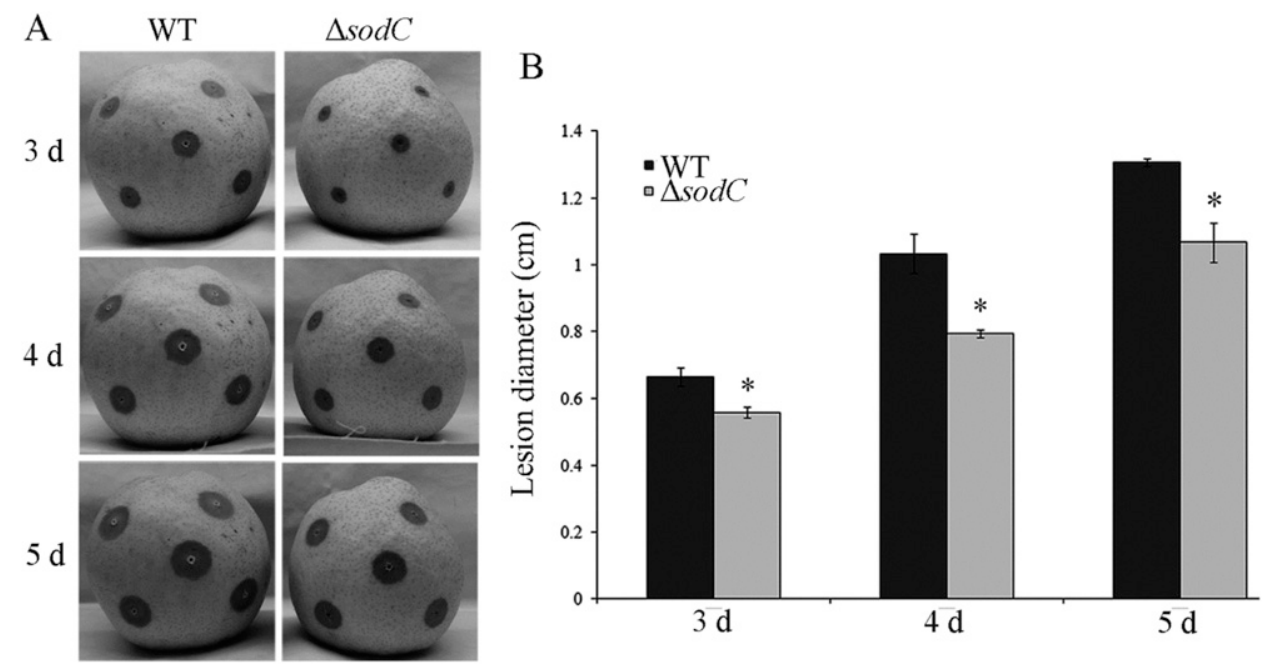

Fig. 6. Pathogenicity of $\Delta s o d C$ mutant on Pyrus bretschneideri. (A) Photographs of P. bretschneideri fruit inoculated with the spores of wild type Aspergillus niger MA 70.15 (WT) and the $\Delta$ sodC for $5 \mathrm{~d}$. (B) Lesion diameter caused by wild type A. niger MA 70.15 (WT) and $\Delta$ sodC on P. bretschneideri fruit as shown in A. Values are mean $\pm \mathrm{SD}(n=15)$. 
defect in decomposing background level of superoxide anion (Fig. 5A). Besides, menadione also induced higher level of $\mathrm{H}_{2} \mathrm{O}_{2}$ in $\triangle$ sodC cells in comparison with wild type cells (Fig. 5B). MDA, which is an index of lipid peroxidation, was determined in menadione-treated cell. As shown in Fig. 5C, the content of MDA in wild type increased slightly along with treatment time; however, MDA accumulated more in $\Delta$ sodC cells.

SODC GENE IS INDISPENSIBLE FOR THE FULL VIRULENCE OF $\boldsymbol{A}$. NIGER. To evaluate whether sodC gene is involved in the virulence of $A$. niger on fruit, spores were inoculated on chinese white pear fruit. As shown in (Fig. 6A and B), after being infected by $A$. niger, the lesion diameter caused by $A$. niger increased gradually. However, lesion diameter caused by $\triangle$ sodC mutant was significantly smaller than that of wild type, suggesting that sodC gene is indispensible for the full virulence of $A$. niger.

LACK OF SODC ALTERS ROS ACCUMULATION AND MDA IN FRUIT UPON $\boldsymbol{A}$. NIGER INFECTION. To study the response of chinese white pear to wild type $A$. niger and $\triangle$ sodC cells, ROS metabolism was analyzed by the determination of superoxide anion production and contents of $\mathrm{H}_{2} \mathrm{O}_{2}$ and MDA. Superoxide anion production in chinese white pear fruit increased upon $A$. niger infection in both wild type and $\Delta \operatorname{sod} C$, whereas wild type $A$. niger induced a stronger response of superoxide anion in comparison with $\Delta$ sodC (Fig. 7A). As shown in Fig. 7B, an accumulation of $\mathrm{H}_{2} \mathrm{O}_{2}$ occurred in chinese white pear infected with wild type $A$. niger, while the accumulation was attenuated in $\Delta \operatorname{sod} C$-inoculated chinese white pear fruit. Besides, $A$. niger inoculation increased the content of MDA in chinese white pear fruit subjected to both wild type and $\Delta$ sodC. However, MDA content in $\Delta s o d C$-inoculated chinese white pear fruit was significantly lower than that of wild type (Fig. 7C).

\section{Discussion}

Aspergillus rot (black mold rot) is one of the most important postharvest diseases of fruit and vegetable, and $A$. niger is known to cause the most severe symptoms (Hasan, 2000). Although a lot of work has been done to improve the ability of being a cell factory for a range of products, such as enzymes and organic acids (Archer, 2000), the knowledge on the factors determining its pathogenesis on fruit is very limited.

In this study, we indentified sodC gene as a $\mathrm{Cu} / \mathrm{Zn}$-SOD coding gene from $A$. niger. $\mathrm{Cu} / \mathrm{Zn}-\mathrm{SODs}$ are usually located in cytosol and can protect cells from oxidative stress (Holdom et al., 1996). sodC gene was deleted in $A$. niger by gene deletion via homologous recombination. The decreased SOD activity in $\triangle$ sodC mutant compared with wild type confirmed that $\operatorname{sod} C$ did contribute to the total enzyme activity. As SOD is responsible for the superoxide disproportionation reaction during oxidative stress (Chary et al., 1994), we test the sensitivity of $\Delta$ sodC mutant to oxidative stress. Our results indicate that menadione, a generator of intracellular superoxide anion, could significantly inhibit the mycelium growth of $\Delta \operatorname{sodC}$. Further results showed that spore germination of the $\Delta \operatorname{sod} C$ was significantly inhibited by menadione and $\mathrm{H}_{2} \mathrm{O}_{2}$ compared with that of wild type (Fig. 4). All of these indicate that the ability of detoxifying superoxide radicals and even $\mathrm{H}_{2} \mathrm{O}_{2}$ was attenuated in $\Delta$ sodC mutant and sodC gene did contribute to cell's resistance to oxidative stress. Consistently, B. cinerea mutants with SOD1 deletion showed increased sensitivity to ROS-generating agent paraquat (Rolke et al., 2004). Besides, Sclerotinia sclerotiorum mutation in SSSOD1 showed growth rate and sclerotial formation similar to that of the wild type but showed increased sensitivity to heavy metal toxicity and oxidative stress (Xu and Chen, 2013). To further study the attenuated tolerance of $\Delta s o d C$ toward menadione, superoxide anion production and contents of $\mathrm{H}_{2} \mathrm{O}_{2}$, and MDA are determined in menadione-treated $A$. niger. It is found that ROS and MDA increased in $A$. niger with menadione treatment, while they accumulated more in $\Delta$ sodC cells (Fig. 5). Thus, we provide evidence that $\Delta$ sodC cells have defect in response to menadione stress because of failure in ROS decomposition and increased lipid peroxidation.

ROS burst occurs as one of the earliest cellular response after successful pathogen recognition (Torres et al., 2006). Accordingly, fungi pathogens need to activate their antioxidant
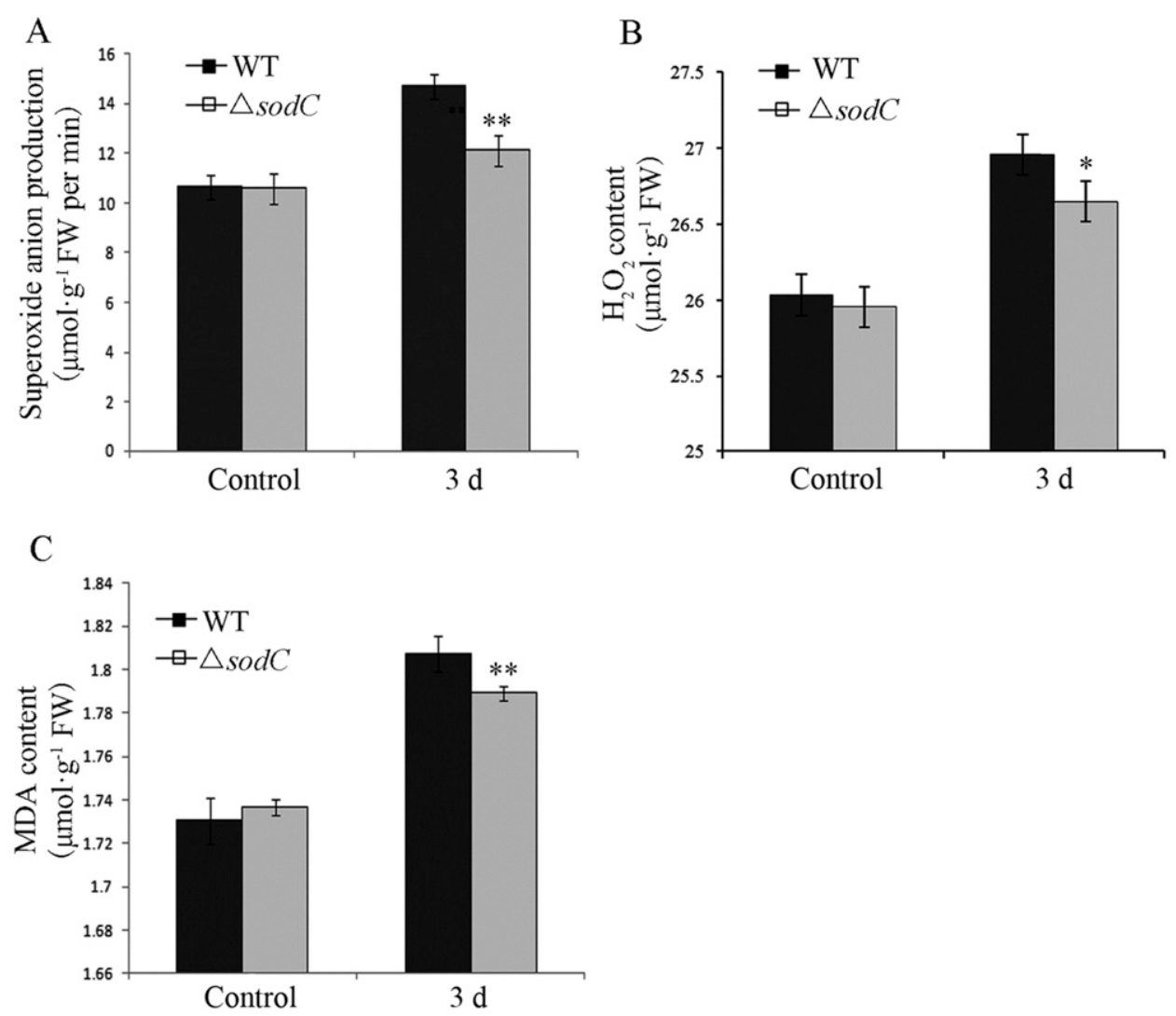

Fig. 7. Superoxide anion production (A) and content of $\mathrm{H}_{2} \mathrm{O}_{2}$ (B) and malondialdehyde (MDA) (C) in Pyrus bretschneideri inoculated with wild type Aspergillus niger MA 70.15 (WT) and $\Delta$ sodC. P. bretschneideri was inoculated with $A$. niger MA 70.15 (WT) and $\Delta$ sodC and were sampled immediately (Control) or on day 3 postinoculation. Values are mean $\pm \operatorname{SD}(n=3)$. 
defenses to cope with the oxidative stress encountered during infection. SODs constitute the primary cellular antioxidant defense system by detoxifying oxygen radicals and we propose that $\mathrm{Cu} / \mathrm{Zn}$-SOD might be a virulence factor for $A$. niger during infection on fruit. In this study, the spores of $\Delta$ sod $C$ mutant were inoculated on chinese white pear fruit. The decreased lesion diameter caused by $\Delta$ sod $C$ suggests that $\mathrm{Cu} / \mathrm{Zn}-\mathrm{SOD}$ contributes to the virulence of $A$. niger (Fig. 6). In normal conditions, antioxidant defense mechanisms are adequate to maintain ROS at basal level and sodC deletion did not make much difference on the growth of $A$. niger. During infection on fruit, $A$. niger may need full function of antioxidant system to cope with oxidative stress due to plant response. $\mathrm{Cu} / \mathrm{Zn}-\mathrm{SOD}$ in $A$. niger is required to detoxify dangerous level of superoxide from host's response to fungal infection and thus we observed the decreased virulence of $\Delta$ sodC mutant. Besides sodC, manganese SOD $\operatorname{sod} B$ in $A$. niger may also contribute to the decomposition of superoxide. There are also other examples of SOD that contribute to virulence in phytopathogenic fungi (Rolke et al., 2004). The deletion of bcsod1 caused smaller lesion and proved that this gene is essential for full virulence of B. cinerea on Arabidopsis thaliana and tomato (Solanum lycopersicum) (López-Cruz et al., 2017; Rolke et al., 2004). Besides, it is also found that SOD1 contributes to the virulence of Fusarium graminearum in wheat (Triticum aestivum) head infection (Yao et al., 2016).

Fruit responses to $A$. niger infection is still unclear. In this work, ROS and MDA content are determined to evaluate whether similar oxidative burst occurs in chinese white pear in response to $A$. niger as observed in other fungi (López-Cruz et al., 2017; Torres et al., 2006). The increased levels of ROS and MDA confirm that $A$. niger infection induces ROS burst in fruits (Fig. 7). Meanwhile, we found that fruit response toward $\triangle$ sodC mutant is attenuated compared with wild type, suggesting the weakened virulence of $\Delta s o d C$ cells. However, it is also reported that plants infected with $\Delta b c s o d l$ accumulated less $\mathrm{H}_{2}$ $\mathrm{O}_{2}$ and more superoxide anion than those infected with wild type (López-Cruz et al., 2017). S. sclerotiorum deletion in Sssodl showed reduced virulence on tomato and tobacco (Nicotania tabacum), but the gene deletion induced a host oxidative burst in adjacent uninfected cells in contrast to reduced ROS production during wild-type infection (Veluchamy et al., 2012). These different findings might be due to different plant materials and different fungi used in researches.

In summary, we show that sodC gene in $A$. niger is necessary for the cells' tolerance to exogenous ROS. sodC deletion mutant caused reduced virulence on chinese white pear, which further support the hypothesis that SOD is important for the full virulence of $A$. niger.

\section{Literature Cited}

Angelova, M.B., S.B. Pashova, B.K. Spasova, S.V. Vassilev, and L.S. Slokoska. 2005. Oxidative stress response of filamentous fungi induced by hydrogen peroxide and paraquat. Mycol. Res. 109:150158.

Apel, K. and H. Hirt. 2004. Reactive oxygen species: Metabolism, oxidative stress, and signal transduction. Annu. Rev. Plant Biol. 55:373-399.

Archer, D.B. 2000. Filamentous fungi as microbial cell factories for food use. Curr. Opin. Biotechnol. 11:478-483.

Ballance, D.J. and G. Turner. 1985. Development of a highfrequency transforming vector for Aspergillus nidulans. Gene 36:321-331.
Beauchamp, C. and I. Fridovich. 1971. Superoxide dismutase: Improved assays and an assay applicable to acrylamide gels. Anal. Biochem. 44:276-287.

Benes, S.E., T.M. Murphy, P.D. Anderson, and J.L.J. Houpis. 1995. Relationship of antioxidant enzymes to ozone tolerance in branches of mature ponderosa pine (Pinus ponderosa) trees exposed to longterm, low concentration, ozone fumigation and acid precipitation. Physiol. Plant. 94:124-134.

Boeke, J.D., F. LaCroute, and G.R. Fink. 1984. A positive selection for mutants lacking orotidine- 5 ' -phosphate decarboxylase activity in yeast: 5-fluoro-orotic acid resistance. Mol. Gen. Genet. 197:345346.

Bradford, M.M. 1976. A rapid and sensitive method for the quantitation of microgram quantities of protein utilizing the principle of protein-dye binding. Anal. Biochem. 72:248-254.

Chary, P., D. Dillon, A.L. Schroeder, and D.O. Natvig. 1994. Superoxide dismutase (sod-1) null mutants of Neurospora crassa: Oxidative stress sensitivity, spontaneous mutation rate and response to mutagens. Genetics 137:723-730.

Delmas, S., A. Llanos, J.L. Parrou, M. Kokolski, S.T. Pullan, L. Shunburne, and D.B. Archer. 2014. Development of an unmarked gene deletion system for the filamentous fungi Aspergillus niger and Talaromyces versatilis. Appl. Environ. Microbiol. 80:3484-3487.

Fu, L.H., K.D. Hu, L.Y. Hu, Y.H. Li, L.B. Hu, H. Yan, Y.S. Liu, and H. Zhang. 2014. An antifungal role of hydrogen sulfide on the postharvest pathogens Aspergillus niger and Penicillium italicum. PLoS One 9:e104206.

Gara, L.D., M.C. de Pinto, and F. Tommasi. 2003. The antioxidant systems vis-à-vis reactive oxygen species during plant-pathogen interaction. Plant Physiol. Biochem. 41:863-870.

Gleason, J.E., C.X. Li, H.M. Odeh, and V.C. Culotta. 2014. Speciesspecific activation of $\mathrm{Cu} / \mathrm{Zn} \mathrm{SOD}$ by its CCS copper chaperone in the pathogenic yeast Candida albicans. J. Biol. Inorg. Chem. 19:595-603. Govrin, E.M. and A. Levine. 2000. The hypersensitive response facilitates plant infection by the necrotrophic pathogen Botrytis cinerea. Curr. Biol. 10:751-757.

Gupta, A.S., R.P. Webb, A.S. Holaday, and R.D. Allen. 1993. Overexpression of superoxide dismutase protects plants from oxidative stress (induction of ascorbate peroxidase in superoxide dismutaseoverexpressing plants). Plant Physiol. 103:1067-1073.

Hasan, H.A.H. 2000. Patulin and aflatoxin in brown rot lesion of apple fruit and their regulation. World J. Microbiol. Biotechnol. 16:607612.

Holdom, M.D., R.J. Hay, and A.J. Hamilton. 1996. The Cu,Zn superoxide dismutasesof Aspergillus flavus, Aspergillus niger, Aspergillus nidulans, and Aspergillus terreus: Purification and biochemical comparison with the Aspergillus fumigatus $\mathrm{Cu}, \mathrm{Zn}$ superoxide dismutase. Infect. Immun. 64:3326-3332.

Hu, L.Y., S.L. Hu, J. Wu, Y.H. Li, J.L. Zheng, Z.J. Wei, J. Liu, H.L. Wang, Y.S. Liu, and H. Zhang. 2012. Hydrogen sulfide prolongs postharvest shelf life of strawberry and plays an antioxidative role in fruit. J. Agr. Food Chem. 60:8684-8693.

Hwang, C.S., G.E. Rhie, J.H. Oh, W.K. Huh, H.S. Yim, and S.O. Kang. 2002. Copper- and zinc-containing superoxide dismutase $(\mathrm{Cu} / \mathrm{Zn}$ SOD) is required for the protection of Candida albicans against oxidative stresses and the expression of its full virulence. Microbiology 148:3705-3713.

Lazar, E.E., R.B. Wills, B.T. Ho, A.M. Harris, and L.J. Spohr. 2008. Antifungal effect of gaseous nitric oxide on mycelium growth, sporulation and spore germination of the postharvest horticulture pathogens, Aspergillus niger, Monilinia fructicola, and Penicillium italicum. Lett. Appl. Microbiol. 46:688-692.

Liu, X.F., I. Elashvili, E.B. Gralla, J.S. Valentine, P. Lapinskas, and V.C. Culotta. 1992. Yeast lacking superoxide dismutase. Isolation of genetic suppressors. J. Biol. Chem. 267:18298-18302.

López-Cruz, J., C.S. Óscar, F.C. Emma, G.A. Pilar, and G.B. Carmen. 2017. Absence of $\mathrm{Cu}-\mathrm{Zn}$ superoxide dismutase BCSOD1 reduces Botrytis cinerea virulence in Arabidopsis and in tomato plants, 
revealing interplay among reactive oxygen species, callose and signalling pathways. Mol. Plant Pathol. 18:16-31.

Moore, S., O.M. de Vries, and P. Tudzynski. 2002. The major $\mathrm{Cu}, \mathrm{Zn}$ SOD of the phytopathogen Claviceps purpurea is not essential for pathogenicity. Mol. Plant Pathol. 3:9-22.

Pel, H.J., J.H. de Winde, D.B. Archer, P.S. Dyer, G. Hofmann, P.J. Schaap, G. Turner, R.P. de Vries, R. Albang, K. Albermann, M.R. Andersen, J.D. Bendtsen, J.A. Benen, M. van den Berg, S. Breestraat, M.X. Caddick, R. Contreras, M. Cornell, P.M. Coutinho, E.G. Danchin, A.J. Debets, P. Dekker, P.W. van Dijck, A. van Dijk, L. Dijkhuizen, A.J. Driessen, C. d'Enfert, S. Geysens, C. Goosen, G.S. Groot, P.W. de Groot, T. Guillemette, B. Henrissat, M. Herweijer, J.P. van den Hombergh, C.A. van den Hondel, R.T. van der Heijden, R.M. van der Kaaij, F.M. Klis, H.J. Kools, C.P. Kubicek, P.A. van Kuyk, J. Lauber, X. Lu, M.J. van der Maarel, R. Meulenberg, H. Menke, M.A. Mortimer, J. Nielsen, S.G. Oliver, M. Olsthoorn, K. Pal, N.N. van Peij, A.F. Ram, U. Rinas, J.A. Roubos, C.M. Sagt, M. Schmoll, J. Sun, D. Ussery, J. Varga, W. Vervecken, P.J. van de Vondervoort, H. Wedler, H.A. Wösten, A.P. Zeng, A.J. van Ooyen, J. Visser, and H. Stam. 2007. Genome sequencing and analysis of the versatile cell factory Aspergillus niger CBS 513.88. Nat. Biotechnol. 25:221-231.

Raulo, R., M. Kokolski, and D.B. Archer. 2016. The roles of the zinc finger transcription factors $X \ln R, C l r A$ and $C l r B$ in the breakdown of lignocellulose by Aspergillus niger. AMB Express 6:5.

Rolke, Y., S. Liu, T. Quidde, B. Williamson, A. Schouten, K.M. Weltring, V. Siewers, K.B. Tenberge, B. Tudzynski, and P. Tudzynski.
2004. Functional analysis of $\mathrm{H}_{2} \mathrm{O}_{2}$-generating systems in Botrytis cinerea: The major $\mathrm{Cu}-\mathrm{Zn}$-superoxide dismutase (BCSOD1) contributes to virulence on french bean, whereas a glucose oxidase (BCGOD1) is dispensable. Mol. Plant Pathol. 5:17-27.

Torres, M.A., J.D.G. Jones, and J.L. Dangl. 2006. Reactive oxygen species signaling in response to pathogens. Plant Physiol. 141:373378.

Vallino, M., E. Martino, F. Boella, C. Murat, M. Chiapello, and S. Perotto. 2009. $\mathrm{Cu}, \mathrm{Zn}$ superoxide dismutase and zinc stress in the metal-tolerant ericoid mycorrhizal fungus Oidiodendron maius $\mathrm{Zn}$. FEMS Microbiol. Lett. 293:48-57.

van Leeuwen, M.R., P. Krijgsheld, R. Bleichrodt, H. Menke, H. Stam, J. Stark, H.A. Wösten, and J. Dijksterhuis. 2013. Germination of conidia of Aspergillus niger, is accompanied by major changes in RNA profiles. Stud. Mycol. 74:59-70.

Veluchamy, S., B. Williams, K. Kim, and M.B. Dickman. 2012. The $\mathrm{CuZn}$ superoxide dismutase from Sclerotinia sclerotiorum is involved with oxidative stress tolerance, virulence, and oxalate production. Physiol. Mol. Plant Pathol. 78:14-23.

$\mathrm{Xu}, \mathrm{L}$. and W. Chen. 2013. Random T-DNA mutagenesis identifies a $\mathrm{Cu} / \mathrm{Zn}$ superoxide dismutase gene as a virulence factor of Sclerotinia sclerotiorum. Mol. Plant Microbe Interact. 26: 431-441.

Yao, S.H., Y. Guo, Y.Z. Wang, D. Zhang, L. Xu, and W.H. Tang. 2016. A cytoplasmic $\mathrm{Cu}-\mathrm{Zn}$ superoxide dismutase SOD1 contributes to hyphal growth and virulence of Fusarium graminearum. Fungal Genet. Biol. 91:32-42. 